\title{
REAL-TIME INSECT DETECTION AND MONITORING: BREAKING BARRIERS TO AREA-WIDE INTEGRATED MANAGEMENT OF INSECT PESTS
}

\author{
N. A. SCHELLHORN ${ }^{1,2}$ AND L. K. JONES ${ }^{1,2}$ \\ ${ }^{1}$ Commonwealth Scientific and Industrial Research Organisation (CSIRO), \\ Brisbane, Qld, 4001 Australia \\ ${ }^{2}$ RapidAIM PtyLtd; nancy@rapidaim.io
}

\begin{abstract}
SUMMARY
Area-wide integrated pest management (AW-IPM) of insect pests relies on surveillance and communication to estimate wild population size, guide targeted control, and determine the effectiveness of any pest control action. However, knowing where and when pests arrive in real-time, communicating the information quickly, and delivering insect pest control in a coordinated manner are potential barriers to achieving areawide management. Agricultural technology is creating opportunities to remove these barriers, which in turn will facilitate the adoption of AW-IPM. Technology advances in insect surveillance (detection and monitoring), data flow and information communication are being realized, and increasingly becoming commercially available. This technological change is largely being driven by macro-economic trends of increased cost of labour, international agricultural trade and shifting consumer demands, and a confluence of new hardware technologies that free computation from the desktop. As professionals and practitioners of pest management, there is an opportunity to shape technological solutions to remove barriers to AWIPM, and to achieve sustainable pest management across commodities and pests. Yet, the success of the technological solution and its area-wide implementation will depend on the way that we think about the problem (innovation), and the solutions (engineering).
\end{abstract}

Key Words: Insect remote monitoring, automated surveillance, pest trapping, data flow, data visualisation, agricultural technology, innovation, fruit flies, Tephritidae

\section{INTRODUCTION}

Pests of global significance regularly cause economic loss due to their transboundary nature and because they are difficult to manage. They are often highly mobile, fail to recognize property boundaries, reproduce rapidly, and require labour-intensive actions to monitor their arrival and to control their populations. Coordinated, well- 
timed delivery of pest control options is often seen as a solution. This approach is referred to as area-wide integrated pest management (AW-IPM); essentially the control of total target pest populations within a delimited area (Klassen and Vreysen 2021). Successful AW-IPM of insect pests requires often highly coordinated effort, involves a regulatory framework, and integrates multiple pest control tactics (Hendrichs et al. 2007).

Evidence of success of the coordinated actions of many farmers was first shown theoretically by Levins (1969). He introduced the concept of metapopulations and distinguished between the dynamics of a single population and a set of local populations. Levin's theoretical model was motivated by, and applied to, a pest control situation over a large region, in which local populations would fluctuate in asynchrony and generations overlap. The output of the model showed that control measures should be applied synchronously throughout to achieve suppression. Many practical examples, successful and unsuccessful, of pest control applied at an areawide basis have followed (Vreysen et al. 2007; Schellhorn et al. 2015). However, there are many potential barriers to efficient and sustainable AW-IPM such as the inability to know where and when pests arrive, communicating the information on time, and delivering pest control as a rapid response in a coordinated manner.

The AW-IPM relies on three key elements: a) accurate estimates of the pest population across a contiguous area of production and continuously over time, b) efficient communication of the population estimates to pest control managers, and c) dynamic coordination and delivery of the management action to suppress or eradicate the pests. Population estimates are generated by regular inspection of traps, plants, or sentinel animals at fixed or random locations (Southwood 1978). Weekly or fortnightly, the presence of pests or their absence is usually recorded on data sheets in the field, and later entered into an electronic database. Depending on the end user, the information may be communicated within 48 hours of weekly / fortnightly monitoring (e.g. crop agronomists to farm manager) or accumulated in a database for record management needed for historical reflection or a random audit (e.g. government biosecurity).

However, for each of these three elements there are several challenges. Manual inspection of traps is labour-intensive, tedious, and causes delays between insect detection and communication to pest managers. The sampling schedule of 7-21 days allows for pest population persistence and increase without intervention. Communicating insect data in a timely manner from across a contiguous area is unrealistic, unless there is an extensive workforce collecting the insect data and providing it quickly to the pest managers (Enkerlin et al. 2017). Once the end users have the data, delivering pest control in a coordinated manner, which can achieve area-wide suppression, is often logistically challenging, and costly. Up to now, many of these challenges have been mitigated by conducting each element with a centrally organized programme almost exclusively led by governments (Kean et al. 2019). This is certainly true in the case of those integrating the delivery of sterile insects (Dyck et al. 2021). 
Pest population estimates, communication, and coordination are organized centrally with many stakeholder participants, which is seen as essential to the success of area-wide programmes, including those with a Sterile Insect Technique (SIT) component. Compared to the number of pests of global significance, there are relatively few examples of AW-IPM of endemic or established pests (Vreysen et al. 2007) because of these barriers, but that is changing. Barriers to more efficient:

a) pest detection, delimitation and monitoring,

b) data flow,

c) information communication, and

d) coordination of pest control,

are being removed through innovations in digital agriculture technology.

Increasingly the inputs and outputs in primary productions systems are being tracked, measured and analysed by automated or partially automated systems. These new technologies increase efficiencies, reduce labour costs and speed up capabilities for decision making. The pressure to continue developing these technologies is driven by global food and fibre demand, market access and traceability issues, and the approaching horizon of resource limitation (FAO 2017). The result of this is that more and more farms are connected and networked, and that data flow is moving away from the notebook and into digital information systems. This is critical in the case of early detection and rapid response to invasive species.

Venture capital investment in agricultural technology is on an exponential growth trajectory. For example, investment in early stage companies in Australia, Canada, Israel, and New Zealand has increased from USD 5.8 million in 2010 to USD 89.5 million in 2017. Growth areas include crop protection and input management, precision agriculture and imagery (Finistere Ventures 2018).

Technology is providing opportunities to achieve greater efficiencies for on-farmand AW-IPM. Advances have been made in data flow, real-time insect surveillance (detection and monitoring), information communication, and mating disruption by using automated pheromone dispensers. Over that last decade, automation of pest surveillance and taxonomic identification, especially for tephritid fruit flies, has emerged in research institutions and the commercial market (Jiang et al. 2008; Liu et al. 2009; Faria et al. 2014; Philimis 2015; Doitsidis et al. 2017; Goldshtein et al. 2017; Potamitis et al. 2017a, 2017b; Shaked et al. 2018). However, in order for the implementation and adoption of area-wide automated insect surveillance to occur, two spheres will need to align: the way we think about the problem (innovation), and the way we solve the problem (engineering). How we bring these two spheres together will be critical to achieving efficient detection of exotic pest incursions, monitoring of endemic populations, and their control.

Here we focus on why we want to bring innovation and engineering together to achieve efficient and effective AW-IPM, what methodologies are currently on the market, and how current and future technological solutions will contribute to more efficient and effective pest suppression and eradication. 


\section{THE PROBLEM AND THE SOLUTION}

\subsection{Significant Barriers to Area-wide Suppression}

"Innovation in all aspects of modern life is seen as a socio-economic cure for many of the troubles of modern societies" (Ferguson et al. 2014).

One of the great troubles of modern society is achieving environmentally acceptable and economically sustainable pest management of food and fibre crops. This is especially true for managing highly mobile, invasive insect pests. The AW-IPM of economically important pests is viewed as a promising solution. Yet, to achieve areawide pest suppression one needs to overcome significant potential barriers including:

a) support from many stakeholders, the community and public (including standardised approaches/methodologies across diverse stakeholder groups),

b) knowing where and when pests show up, and

c) the dynamics of pest populations in target landscapes that are heterogeneous in space and time.

Technological innovation offers solutions to overcome these challenges, making AW-IPM accessible for the management of numerous pests by communities and grower groups, and as well as increasing the efficiency and effectiveness of programmes that integrate the SIT. Logistical barriers can be reduced and eliminated to improve insect detection and monitoring, data flow, communication, and coordination of area-wide pest control.

\subsection{The Innovative Solutions to Barriers of Efficient and Effective AW-IPM}

The methodologies for in-field data collection of insect populations have barely changed since estimates began and these are well captured in classic references such as Southwood's 1978 "Ecological Methods"; visual counts, sweep nets, pitfall traps, destructive sampling of fruits, and lure-based insect traps are the standard. Generating population density estimates using these approaches is tedious, laborious, and restricted to snapshots in time and space. The data are collected in the field, then returned to the laboratory for manual entry into spreadsheets for later data checking and analysis of trends; a slow in-flow of data, which means a slow out-flow of information.

One of the most recent advances to speed up data flow is in-field electronic data entry. As of 2017 there have been approximately 30 downloadable mobile scouting apps for in-field data collection, a large proportion of which can be used to collect arthropod population data (Hopkins 2017). This technology is increasingly being used across the public and private sectors. Tablet or smartphone applications allow government officers and commercial pest control advisers to enter geo-referenced information at the location of data collection. By scanning a barcode on an insect trap, or geo-referencing a field scout's location, field staff can enter the insect count data on the device, which is then uploaded on a server in an easily readable format such as an Excel spreadsheet. 
End users now have the option to use open source software to tailor data collection applications. A widely used example is the Open Data Kit (ODK) Project developed at The University of Washington (users range from individual researchers to Google and the World Health Organization). The project provides tools for a community of users to both create data collection apps and to contribute to the development of the software code. Blogs and forums facilitate an iterative process whereby ODK is continually updated by the feedback loop of users and developers actively engaging (ODK 2018). Fit-for-purpose packages are increasingly available as semi-commercial and commercial applications like those developed and used by different government agencies for fruit fly in-field data collection / communication (Table 1).

Table 1. Examples of end-user dashboards for in-field electronic pest data collection

\begin{tabular}{|c|c|c|c|}
\hline Name & Location & Application & Target \\
\hline $\begin{array}{c}\text { CalTraps } \\
\text { http://caltrap-info.com/faqs }\end{array}$ & $\begin{array}{c}\text { Los Angeles } \\
\text { County, USA } \\
\text { originally, now } \\
\text { covering most } \\
\text { California counties }\end{array}$ & $\begin{array}{l}\text { Pest detection } \\
\text { data management } \\
\text { applications }\end{array}$ & $\begin{array}{l}\text { Tephritid fruit } \\
\text { flies }\end{array}$ \\
\hline $\begin{array}{c}\text { Trapbase } \\
\text { https://www.agriculture.vic.gov.au }\end{array}$ & Victoria, Australia & $\begin{array}{l}\text { A Victorian } \\
\text { Government } \\
\text { online database } \\
\text { for recording } \\
\text { fruit fly trap } \\
\text { locations, } \\
\text { monitoring and } \\
\text { mapping of fruit } \\
\text { fly detections }\end{array}$ & $\begin{array}{l}\text { Tephritid fruit } \\
\text { flies }\end{array}$ \\
\hline $\begin{array}{c}\text { OpenScout } \\
\text { www.dtn.com }\end{array}$ & $\begin{array}{l}\text { Indiana, USA, } \\
\text { DTN, formerly } \\
\text { Spensa } \\
\text { Technologies }\end{array}$ & $\begin{array}{l}\text { Field scouting } \\
\text { app; allows end } \\
\text { user to select } \\
\text { insects from a } \\
\text { customizable list }\end{array}$ & $\begin{array}{l}\text { Agronomic } \\
\text { platform with } \\
\text { scouting for } \\
\text { insect pests and } \\
\text { decision } \\
\text { making } \\
\end{array}$ \\
\hline $\begin{array}{c}\text { AgWorld Scout } \\
\text { https://www.farms.com/agriculture- } \\
\text { apps/crops//agworld-scout }\end{array}$ & $\begin{array}{l}\text { Perth, Western } \\
\text { Australia }\end{array}$ & $\begin{array}{l}\text { In-field } \\
\text { assessment to } \\
\text { monitor crop } \\
\text { health and pest } \\
\text { pressure }\end{array}$ & $\begin{array}{l}\text { Custom list of } \\
\text { insects }\end{array}$ \\
\hline $\begin{array}{c}\text { Scoutpro } \\
\text { www.scoutpro.org }\end{array}$ & $\begin{array}{l}\text { Urbandale, Iowa, } \\
\text { USA }\end{array}$ & $\begin{array}{l}\text { Scouting } \\
\text { platform with } \\
\text { built-in ID keys }\end{array}$ & $\begin{array}{l}\text { Developed for } \\
\text { soybean, corn } \\
\text { and wheat }\end{array}$ \\
\hline $\begin{array}{c}\text { Farm Dog } \\
\text { https://farmdog.ag }\end{array}$ & $\begin{array}{l}\text { Salinas, California, } \\
\text { USA }\end{array}$ & $\begin{array}{l}\text { Pest and disease } \\
\text { management } \\
\text { software }\end{array}$ & $\begin{array}{l}\text { Custom list of } \\
\text { insects }\end{array}$ \\
\hline $\begin{array}{c}\text { Koppert iPM Scout app } \\
\text { www.koppertipm.com }\end{array}$ & $\begin{array}{l}\text { Berkel en } \\
\text { Rodenrijs, The } \\
\text { Netherlands }\end{array}$ & $\begin{array}{l}\text { Pest and disease } \\
\text { scouting }\end{array}$ & $\begin{array}{l}\text { Customised } \\
\text { template }\end{array}$ \\
\hline $\begin{array}{c}\text { CropScout } \\
\text { https://www.agric.wa.gov.au } \\
\text { /apps/cropscout }\end{array}$ & $\begin{array}{l}\text { Western Australian } \\
\text { Government }\end{array}$ & $\begin{array}{l}\text { Pest counts } \\
\text { relative to spray } \\
\text { thresholds }\end{array}$ & Canola aphid \\
\hline
\end{tabular}


In-field electronic pest data collection applications improve data flow and remove delays caused by manual data entry of a paper-based collection system, which then has to be entered into an electronic spreadsheet, collated, checked for errors, and presented in a meaningful visualization, which is rarely spatially explicit. In turn these new applications can improve communication among pest control managers and other stakeholders; pest location and density can be visualized spatially across an area allowing for a targeted response and review.

However, two significant barriers remain - the spatial and temporal resolution of the information is coarse due to the limitations of 'boots' on-the-ground, both in terms of the number of locations that can be sampled, and the frequency at which information can be collected. Data interpolation has been the primary means of getting around this issue. Yet, the benefit of the visualization of interpolated data does not translate into location-specific pest management. The scale of interpolated data is too coarse to achieve more targeted insecticide or biocide application. Automated insect detection and monitoring has the potential to address this problem effectively.

\section{THINKING ABOUT THE PROBLEM}

Thorough consideration of the barriers to pest detection and monitoring is needed in order to propose and develop the most useful automated solutions and process for adoption. An engineering solution alone, without the full context of an area-wide management programme, is unlikely to have the anticipated uptake and impact. As one example, trapping grids for pest detection are labour-intensive, therefore a simple solution would be to automate an insect trap to reduce the needs for field visits and labour. However, the result may be a reduced workforce with limited ability to respond rapidly when borders are breached, and an exotic pest invades.

\subsection{Detecting Rare Events and Early Incursions}

Following a detection of fruit flies in a fruit fly free zone, there is a requirement to move quickly and identify the area infested and the area that has remained free from fruit fly. This can be achieved by rapidly deploying traps at a higher density (10-fold increase) and checking the traps more frequently. Such an event often requires additional staff, and the process continues until the area is declared pest-free. Arguably, the problem is the low probability to detect a rare event or early incursion, the challenge to quickly delimit the infested area and deliver control of the infestation, and ultimately to provide sufficient evidence of pest absence.

Solving the problem of detecting rare events and early incursions for a rapid response can minimize the size and duration of the management response, the cost, and the amount of time that markets are closed (Suckling et al. 2016). As two small examples, approximately USD 720000 / week was spent to tackle the Queensland fruit fly, Bactrocera tryoni (Froggatt) incursion into the pest-free state of northern Tasmania, Australia in autumn 2018 (Beavis 2018). In Miami-Dade County Florida, USA, the authorities spent USD 3.5 million in a few months eliminating an outbreak of Bactrocera dorsalis (Hendel), and an estimate of USD 25 million was incurred 
from cost and losses (Alvarez et al. 2016). An outbreak of B. tryoni in New Zealand in 2015 cost USD 9.72 million (BBC 2015).

These examples highlight that an innovative solution for biosecurity is a pest surveillance system that increases the probability of detection of rare events and early incursions; a solution that provides greater spatial and temporal resolution. This would allow a rapid response to contain the geographic extent of the outbreak, and to have confidence of area-freedom during and after control. Technological innovations that can quickly provide solutions to costly problems, such as these, are likely to have tremendous positive impact.

Insect detection solutions that are fast and easy to deploy, provide real-time data flow, and are cost-effective, will be even more significant for managing pests that are endemic and widespread. Pest control solutions across commodities mostly rely on the 'sample, spray and pray' approach, with sampling often being ad hoc (Zalucki et al. 2009). Searching for pests in orchards and crops requires training for correct identification, can be imprecise (how much searching is required to make an informed decision), is tedious and tiring (long periods of time on hands and knees looking at plants) and those who are hired to complete that task can be incentivized from sales of insecticide, not from not spraying. Advocates of IPM promote sustainable practices, but limited adoption of AW-IPM is the reality. The 'sample, spray and pray' principle is standard, and will remain so until practical solutions for insect monitoring and communication are provided. Technological innovation can play a role in breaking down the challenges of poor information about pest numbers, pest locations and effectiveness of insecticide sprays.

\subsection{Trapping Guidelines}

Beyond the technical challenges of automating insect surveillance, consideration must be given to the staffing needs and workplace culture when changes are made to long standing surveillance practices. For major insect pests, especially those that are barriers to trade such as fruit flies, insect trapping guidelines are well established, and harmonized based on the trapping objective, e.g. detecting, delimiting, monitoring, and the desired pest control outcome (FAO/IAEA 2018; ISPM 2018). These recent trapping guidelines are comprehensive and provide a level of detail rarely available for other insect pests.

One of the more challenging aspects of trapping guidelines is trapping density, its dynamic, and changes according to the survey objectives, and the pest species. Lurebased insect traps provide relative estimates expressed as numbers per unit effort and are dependent on many factors. In general, the probability of detecting an individual insect is based on the sampling effort (the number of traps deployed), the size of the target insect population, the activity of the insects, and the insect attractant and trapping device efficiency (Vreysen 2021; FAO/IAEA 2018).

\subsection{Lure-based Trapping Methods}

Lure-based trapping methods are used for many of the major global insect pests for monitoring endemic populations, and for detecting exotic pest incursions, such as 
major fruit fly species (e.g. oriental fruit fly, Queensland fruit fly, Mediterranean fruit fly (Ceratitis capitata (Wiedemann)), other invasive insects (e.g. Japanese beetle, Popillia japonica Newman; tropical gypsy moth, Lymantria pelospila Turner; Asian long-horned beetle, Anoplophora glabripennis (Motschulsky); Khapra beetle, Trogoderma granarium Everts); major endemic pests of field crops (e.g. noctuid armyworm, Pseudaletia unipuncta (Haworth); fall armyworm, Spodoptera frugiperda (Smith); corn earworm, Helicoverpa zea (Boddie)), and pome fruit pests (codling moth, Cydia pomonella (L.); oriental fruit moth, Grapholita molesta (Busck); oblique-banded leafroller, Choristoneura rosaceana (Harris)). These lurebased trapping methods also provide the cornerstone of many SIT programmes, both for delivery of sterile insects (determining release rates) and demonstrating efficacy of control of wild populations.

Lure-based traps estimate the relative density, unless the target's physiological response to the attractant is quantified (Taylor 2018). Relative estimates are expressed as numbers per unit effort and are advantageous over visual estimates by saving time (checking a point location is quicker than random searching of plants and animals), thus increasing efficiency of detection. Lure-based trapping, to generate tephritid population estimates, has limitations in that it is primarily males that are lured, and trapping efficacy can be influenced by various factors, including environmental differences, demographic factors, and the behaviour and physiological state of the individual (Taylor 2018).

Nevertheless, lure-based trapping has become highly specialized and efficient for tephritids (FAO/IAEA 2018). Trapping continues to provide a reliable and easy to use methodology for surveying pests, but also represents a costly and inefficient component of any insect survey programme, be it for government biosecurity or pest management. As an example, the trapping component of SIT-based AW-IPM programmes for Mediterranean fruit fly is estimated to represent $18-25 \%$ of programme costs, which is only partially due to the sorting of captured wild from sterile flies (Enkerlin et al. 1996; FAO/IAEA 2018). The trapping cost can be further reduced with automation, and with the technology of today it may even support SIT programmes by helping to prioritise workflow of staff.

\section{SOLVING THE PROBLEM}

Freeing computation from the desktop has been a key driver that has enabled the development of innovative solutions to automate insect monitoring and detection.

\subsection{Automated Insect Monitoring and Communication Technology}

Thus far, the majority of solutions include camera/s focused on dead insects caught in the bottom of traps or stuck to sticky cards (Table 2). As with manual traps, all of the automated solutions include off-the-shelf pheromones or attractants of the target insects. The camera takes pictures at fixed intervals (e.g. Trapview, Semios), and the software displays the images for the end user to confirm. For some systems, the confirmation process feeds back into the software as a component of the machine learning algorithm for improved automated diagnostics (e.g. Trapview). 
Optical photosensors are being used to discriminate wing-beat frequency of insects entering a trap (e.g. Farmsense and AgroPestAlert). A company established by the authors of this paper use a type of capacitance sensing, similar to a behavioural fingerprint of insects, which detects and discriminates an insect as it enters the trap and delivers the information to mobile app in real-time (Table 2).

Table 2. Examples of automated insect monitoring and communication technology

\begin{tabular}{|c|c|c|c|c|}
\hline Company Name & Location & Type & Target & Product Stage \\
\hline $\begin{array}{c}\text { DTN } \\
\text { (formerly } \\
\text { Spensa Tech) }\end{array}$ & $\begin{array}{l}\text { Purdue, } \\
\text { Indiana, } \\
\text { USA }\end{array}$ & $\begin{array}{l}\text { Sentinel; } \\
\text { camera-fitted } \\
\text { trap }\end{array}$ & $\begin{array}{l}\text { Lepidopterap } \\
\text { ests of pome } \\
\text { fruit }\end{array}$ & $\begin{array}{l}\text { Acquired by DTN April } \\
\text { 2018; Commercial } \\
\text { www.dtn.com }\end{array}$ \\
\hline $\begin{array}{c}\text { DTN } \\
\text { (formerly } \\
\text { Spensa Tech) }\end{array}$ & $\begin{array}{l}\text { Purdue, } \\
\text { Indiana, } \\
\text { USA }\end{array}$ & $\begin{array}{l}\text { Z-Trap; } \\
\text { electromagnetic } \\
\text { current inside } \\
\text { delta trap }\end{array}$ & $\begin{array}{l}\text { Lepidopterap } \\
\text { ests of pome } \\
\text { fruit }\end{array}$ & $\begin{array}{l}\text { Acquired by DTN April } \\
\text { 2018; Commercial } \\
\text { www.dtn.com }\end{array}$ \\
\hline TrapView & $\begin{array}{l}\text { Hrusevje, } \\
\text { Slovenia }\end{array}$ & $\begin{array}{l}\text { Camera-fitted } \\
\text { traps in various } \\
\text { designs }\end{array}$ & $\begin{array}{l}\text { Lepidoptera } \\
\text { and Diptera }\end{array}$ & $\begin{array}{l}\text { Commercial } \\
\text { www.trapview.com }\end{array}$ \\
\hline SnapTrap & $\begin{array}{l}\text { Victoria, } \\
\text { Australia }\end{array}$ & $\begin{array}{l}\text { Camera-fitted } \\
\text { traps }\end{array}$ & Fruit fly & $\begin{array}{l}\text { Commercial } \\
\text { www.snaptrap.com }\end{array}$ \\
\hline $\begin{array}{c}\text { SemiosBio } \\
\text { Technologies } \\
\text { Inc. }\end{array}$ & $\begin{array}{l}\text { Vancouver, } \\
\text { British } \\
\text { Columbia, } \\
\text { Canada }\end{array}$ & $\begin{array}{l}\text { Variable rate } \\
\text { mating } \\
\text { disruption and } \\
\text { automated pest } \\
\text { camera trap }\end{array}$ & $\begin{array}{l}\text { Lepidopterap } \\
\text { ests of fruit } \\
\text { and nuts; CA } \\
\text { red scale }\end{array}$ & $\begin{array}{l}\text { Commercial } \\
\text { www.semios.com }\end{array}$ \\
\hline $\begin{array}{c}\text { iScout } \\
\text { (Pessl } \\
\text { Instruments) }\end{array}$ & $\begin{array}{l}\text { Graz, } \\
\text { Austria }\end{array}$ & $\begin{array}{l}\text { Camera-fitted } \\
\text { sticky trap }\end{array}$ & Non-specific & $\begin{array}{l}\text { Commercial } \\
\text { http://www.pesslinstru } \\
\text { ments.com/ }\end{array}$ \\
\hline $\begin{array}{c}\text { RapidAIM Pty } \\
\text { Ltd. }\end{array}$ & $\begin{array}{l}\text { Brisbane, } \\
\text { Queensland, } \\
\text { Australia }\end{array}$ & $\begin{array}{l}\text { Novel } \\
\text { capacitance- } \\
\text { type sensor }\end{array}$ & $\begin{array}{l}\text { Fruit fly for } \\
1 \text { st product }\end{array}$ & $\begin{array}{l}\text { Commercial } \\
\text { www.rapidaim.io }\end{array}$ \\
\hline AgroPestAlert & $\begin{array}{l}\text { Tudela, } \\
\text { Spain }\end{array}$ & $\begin{array}{l}\text { Photosensor- } \\
\text { wing-beat } \\
\text { frequency }\end{array}$ & Non-specific & $\begin{array}{l}\text { Prototype } \\
\text { http://agropestalert.com } \\
\text { / }\end{array}$ \\
\hline Farmsence Inc. & $\begin{array}{l}\text { Riverside, } \\
\text { CA, USA }\end{array}$ & $\begin{array}{l}\text { Optical - wing- } \\
\text { beat frequency }\end{array}$ & Lepidoptera & $\begin{array}{l}\text { Prototype } \\
\text { www.farmsense.io }\end{array}$ \\
\hline
\end{tabular}

Electromagnetic current is used by Spensa Tech for monitoring lepidopteran orchard pests. The current from the 'Z-trap' surrounds and kills the insect, and the amount of current provides an indication of the insect size, as a surrogate for the insect's identity. 
There are key considerations when adopting automated monitoring and communication technology, and these will differ depending on the objectives of the programme, and of the end users. However, general criteria include the reliability of detection, reliability of communicating the detection, efficacy of insect capture compared to an industry standard, efficiency compared to manual trapping, and the added value, for example, how real-time data flow allows for rapid response, which ultimately reduces costs of managing outbreaks, and minimizes disruption to trade.

Technology is rarely neutral, and the expectations of the benefits will need to align with the problem that is being solved. For example, if the expectation is that automation will replace humans, then it's unlikely that automation will ever be developed at a level that is cost-effective. However, if the expectation is that automation is providing better information for more informed pest management decisions, improving workflow, and reducing the harm from exotic pest incursions, then there are already technologies that can advance pest detection and monitoring (Table 2). Automated systems are already improving data flow into geographic information system (GIS) databases, in turn allowing real-time visualisation for managers and stakeholders of insect population hot spots and areas under control, and ultimately providing tighter feedback in detection, communication, control application and validation (Fig. 1).

\section{Manual Monitoring}

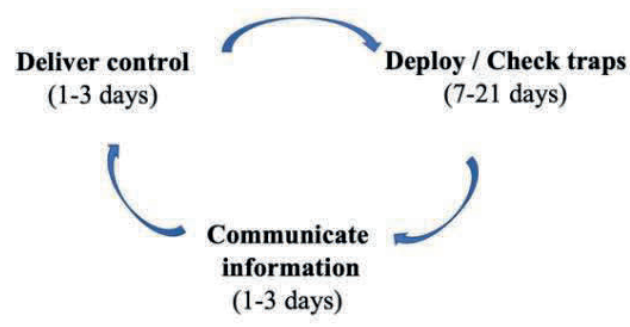

9-28 day feedback loop

\section{Real-time Monitoring}



2-4 day feedback loop

Figure 1. Feedback loop comparing manual and real-time monitoring.

\subsection{Coordinating Data Flow, Control and Evaluation}

For many decades, theory has demonstrated that for pest population control measures to be effective within AW-IPM, synchronicity at temporal and spatial scales is paramount (Levins 1969; Ives and Settle 1997). Surveillance methodology and strategy, if it is to be effective within AW-IPM, needs also to be synchronous across insect present and potential distribution areas. Some of the pitfalls of manual monitoring are the variations in methodology between stakeholders, as well as human error, and the large and complex chain that data progress through from field collection to management action. 
Digitising and standardising data flow at all levels may greatly reduce the loss of data fidelity and allow for the level of dynamism that is required in large complex systems. Examples of where this model has been effectively rolled out at large scales are found within clinical data systems. The transition of medical data records from paper to personal computers to medical data collection apps has accelerated in the past 10 years (Zhang et al. 2017). So much so that clinician end user demand has driven the standardisation of digital health record-keeping at all levels of the data supply chain (FDA 2018).

Empirical examples have shown the benefit of synchronicity in pest control and include coordinated timing of insecticide application (Smith 1998; Lloyd et al. 2010), coordinated growing of trap crops (Sequeira 2001), area-wide release of sterile insects (Hendrichs et al. 1995), coordinated orchard hygiene (Lloyd et al. 2010), and sanitation methods to destroy a life stage, such as pupae in soil, to achieve area-wide reduction in pest populations (Duffield 2004; Lloyd et al. 2008). Some of these examples achieve coordination by default due to the narrow window of suitability of the action, e.g. as defined by the license for growing genetically modified cotton in Australia. However, area-wide data collection, data flow, and coordinating pest management of insecticide/biocide/biological application (sterile insects and natural enemies) has been logistically impossible without a central coordinating body and a regulatory framework. This has resulted in independent, asynchronous delivery of insecticide for marginal gain.

Fruit and vegetable production regions are often characterised by long growing seasons, diverse commodities, and polyphagous pests (such as tephritid fruit flies) that take advantage of these spatially and temporally heterogeneous landscapes that span the urban and rural habitats (Schwarzmueller et al. 2019). Often urban landscapes provide permanent low-density resources, such as a variety of backyard trees as potential pest hosts. Even though host plant density and diversity is much lower than in a commercial orchard setting, these urban environments can significantly contribute to high and persistent pest populations because populations are often uncontrolled and backyard hosts can fill the seasonal gaps by providing continuity of resources for pests (Schwarzmueller et al. 2019).

Beyond the biophysical challenges of AW-IPM in diverse landscapes are the psychosocial barriers for those who are directly (growers) and indirectly (regional towns people) affected by the pests. One of the greatest barriers to acceptance of communities participating in area-wide management of Queensland fruit fly was lack of social cooperation amongst growers such as insufficient care and responsibility about their role in the broader horticultural and social systems (Mankad et al. 2017). Increased transparency of the problems and issues for all actors, including better insights into knowing when pests show up, and where pests are located, may enable coordinated control and validation as to whether the AW-IPM actions are effectively suppressing the target population. 


\section{CONCLUSIONS}

The inability to know where and when pests arrive, as well as their population dynamics in space and time, the inability to communicate this information in a timely manner and delivering coordinated pest control are barriers to AW-IPM, and in turn, potential barriers to efficient and sustainable pest management.

Increasingly technologies that free complex computation from desktop computing to in-field mobile devices are central to the development of in-field data collection, and automated insect detection and monitoring. Each of these will enable information communication among stakeholders, and the area-wide coordination of pest control.

Engineering solutions to overcome these barriers are many and varied. For government biosecurity, detecting rare events of pest incursions or escapees can minimize the size and duration of the management response, the cost, and the amount of time that markets are closed. For pest management of endemic species, automated insect detection solutions that are fast and easy to deploy, that provide real-time data flow, and that are cost-effective, can have a significant impact by improving estimates of pest numbers, pest locations and effectiveness of integrated control.

Even if it is early days, current in-field data collection and insect automation technology is already providing better information for more informed pest management decisions, improved workflow, and has the potential to reduce the harm from exotic pest incursions.

\section{REFERENCES}

Alvarez, S., E. A. Evans, and A. W. Hodges. 2016. Estimated costs and regional economic impacts of the Oriental fruit fly (Bactrocera dorsalis) outbreak in Miami-Dade County, Florida. University of Florida IFAS Extension. Fe988. Gainesville, Florida, USA.

(BBC) British Broadcasting Corporation. 2015. New Zealand: Officials declare victory over fruit fly.

Beavis, L. 2018. Tasmania's fruit fly fight hits $\$ 5.5$ million bill, but Minister expects victory.

Doitsidis, L., N. Fouskitakis, N. K. Varikou, I. I. Rigakis, S. A. Chatzichristofis, A. K. Papfilippaki, and A. E. Birouraki. 2017. Remote monitoring of the Bactorcera oleae (Gmelin) (Diptera: Tephritidae) population using an automated McPhail trap. Computers and Electronics in Agriculture 137: 69-78

Duffield, S. 2004. Evaluation of the risk of overwintering Helicoverpa spp. pupae under irrigated summer crops in southwestern Australia and the potential for area-wide management. Annals of Applied Biology 144: 17-26.

Dyck, V. A., J. Reyes Flores, M. J. B. Vreysen, E. E. Regidor Fernández, B. N. Barnes, M. Loosjes, P. Gómez Riera, T. Teruya, and D. Lindquist. 2021. Management of area-wide pest management programmes that integrate the Sterile Insect Technique, pp. 781-814. In V. A. Dyck, J. Hendrichs, and A. S. Robinson (eds.), Sterile Insect Technique - Principles and practice in Area-Wide Integrated Pest Management. Second Edition. CRC Press, Boca Raton, Florida, USA.

Enkerlin, W. R., L. Lopez, and H. Celedonio. 1996. Increased accuracy in discrimination between captured wild unmarked and released dye-marked adults in fruit fly (Diptera: Tephritidae) sterile released programs. Journal of Economic Entomology 89: 946-949.

Enkerlin, W. R., J. M. Gutiérrez Ruelas, R. Pantaleon, C. Soto Litera, A. Villaseñor Cortés, J. L. Zavala López, D. Orozco Dávila, P. Montoya Gerardo, L. Silva Villarreal, E. Cotoc Roldán, F. Hernández López, A. Arenas Castillo, D. Castellanos Dominguez, A. Valle Mora, P. Rendón Arana, C. Cáceres Barrios, D. Midgarden, C. Villatoro Villatoro, E. Lira Prera, O. Zelaya Estradé, R. Castañeda Aldana, J. López Culajay, F. Ramírez y Ramírez, P. Liedo Fernández, G. Ortíz Moreno, J. Reyes Flores, and J. Hendrichs. 2017. The Moscamed regional programme: Review of a success story of area-wide Sterile Insect Technique application. Entomological Experimentalis et Applicata 164: 188-203. 
Faria, F. A., P. Perre, R. A. Zucchi, L. R. Jorge, T. M. Lewinsohn, A. Rocha, and R. da Silva Torres. 2014. Automatic identification of fruit flies (Diptera: Tephritidae). Journal of Visual Communication Image Research 25: 1516-1527.

(FAO) Food and Agriculture Organization of the United Nations. 2017. The future of food and agriculture - Trends and challenges. Rome, Italy.

(FAO/IAEA) Food and Agriculture Organization of the United Nations/International Atomic Energy Agency. 2018. Trapping guidelines for area-wide fruit fly programmes. W. R. Enkerlin, and J. ReyesFlores, J. (eds.). Second Edition. Rome, Italy. 65 pp.

Ferguson, D. M., S. Purzer, M. W. Ohland, and K. Jablokow. 2014. The traditional engineer vs the innovative engineer. In 121st American Society of Engineering Education Annual Conference \& Exposition Paper ID \#8751. June 15-18, 2014. Indianapolis, Indiana, USA.

(FDA) Food and Drug Administration. 2018. Use of electronic health record data in clinical investigations: Guidance for industry. US Department of Health and Human Services.

Finistere Ventures. 2018. Early-stage Agtech report. Palo Alto, California, USA.

Goldshtein, E., Y. Cohen, A. Hetzroni, Y. Gazit, D. Timar, L. Rosenfeld, Y. Grinshpon, A. Hoffman, and A. Mizrach. 2017. Development of an automatic monitoring trap for Mediterranean fruit fly (Ceratitis capitata) to optimize control applications frequency. Computers and Electronics in Agriculture 139: 115-125.

Hendrichs, J., G. Franz, and P. Rendon. 1995. Increased effectiveness and applicability of the Sterile Insect Technique through male-only releases for control of Mediterranean fruit flies during fruiting season. Journal of Applied Entomology 119: 371-377.

Hendrichs, J., P. Kenmore, A. S. Robinson, and M. J. B. Vreysen. 2007. Area-Wide Integrated Pest Management (AW-IPM): Principles, practice and prospects, pp. 3-34. In M. J. B. Vreysen, A. S. Robinson, and J. Hendrichs (eds.), Area-wide control of pests: From research to field implementation. Springer Dordrecht, The Netherlands.

Hopkins, M. 2017. 17 field scouting apps for precision agriculture. Meister Media Worldwide.

(ISPM) International Standard for Phytosanitary Measures. 2018. Establishment of pest free areas for fruit flies (Tephritidae). ISPM 26, International Plant Protection Convention, FAO. Rome, Italy.

Ives, A. R., and W. H. Settle. 1997. Metapopulation dynamics and pest control in agricultural systems. American Naturalist 149: 220-246.

Jiang, J.-A., C.-L. Tseng, F.-M. Lu, E.-C. Yang, Z.-S. Wu, C.-P. Chen, S. Lin, L.-C. Lin, and C.-S. Liao. 2008. A GSM-based remote wireless automated monitoring system for field information: A case study for ecological monitoring of the Oriental fruit fly (Bactrocera dorsalis Hendel). Computers and Electronics in Agriculture 62: 243-259.

Kean, J. M., D. M. Suckling, N. J. Sullivan, P. C. Tobin, L. D. Stringer, G. R. Smith, B. Kimber, D. C. Lee, R. Flores Vargas, J. Fletcher, F. Macbeth, D. G. McCullough, D. A. Herms, et al. 2019. Global eradication and response database (GERDA).

Klassen, W., and M. J. B. Vreysen. 2021. Area-Wide Integrated Pest Management and the Sterile Insect Technique, pp. 75-112. In V.A. Dyck, J. Hendrichs, and A.S, Robinson (eds.), Sterile Insect Technique - Principles and practice in Area-Wide Integrated Pest Management. Second Edition. CRC Press, Boca Raton, Florida, USA.

Levins, R. 1969. Some demographic and genetic consequences of environmental heterogeneity for biological control. Bulletin of Entomological Society of America 15: 237-240.

Liu, Y., J. Zhang, M. Richards, B. Pham, P. Roe, and A. Clarke. 2009. Towards continuous surveillance of fruit flies using sensor networks and machine vision. $5^{\text {th }}$ International Conference on Wireless Communications, Networking and Mobile Computing. September 2009, Beijing, China.

Lloyd, A. C., E. I. Hamacek, R. A. Kopittke, T. Peek, P. M. Wyatt, C. J. Neale, M. Eelkema, and H. Gu. 2010. Area-wide management of fruit flies (Diptera: Tephritidae) in the Central Burnett district of Queensland, Australia. Crop Protection 29: 462-469.

Lloyd, R. J., D. A. H. Murray, J. E. and Hopkinson. 2008. Abundance and mortality of overwintering pupae of Helicoverpa armigera (Hubner) (Lepidoptera: Noctuidae) on the Darling Downs, Queensland, Australia. Australia Journal of Entomology 47: 297-306.

Mankad, A., B. Loechel, and P. F. Measham. 2017. Psycosocial barriers and facilitators for area-wide management of fruit fly in southeastern Australia. Agronomy for Sustainable Development 37: 67(112).

(ODK) Open Data Kit Community. 2018. Open Data Kit. Washington, DC, USA. 
Philimis, P. 2015. E-FLYWATCH Development of an innovative automated and wireless trap with warning and monitoring modules for integrated management of the Mediterranean (Ceratitis capitata) \& olive (Dacus oleae) fruit flies. Final report project reference: 262362. CORDIS - EU Research Projects under Horizon 2020. European Commission.

Potamitis, I., P. Eliopoulos, and I. Rigakis. 2017a. Automated remote insect surveillance at a global scale and the internet of things. Robotics 6: 19.

Potamitis, I., I. Rigakis, and N.-A. Tatlas. 2017b. Automated surveillance of fruit flies. Sensors 17: 110.

Schellhorn, N. A., H. R. Parry, S. Macfadyen, Y. Wang, and M. P. Zalucki. 2015. Connecting scales: Achieving in-field pest control from areawide and landscape ecology studies. Insect Science 22: 35 51.

Schwarzmueller, F., N. A. Schellhorn, and H. R. Parry. 2019. Resource landscapes and movement strategy shape Queensland fruit fly population dynamics. Landscape Ecology 34: 2807-2822.

Sequeira, R. 2001. Inter-seasonal population dynamics and cultural management of Helicoverpa spp. in a central Queensland cropping system. Australian Journal of Experimental Agriculture 41: 49-247.

Shaked, B., A. Amore, C. Ioannou, F. Valdés, B. Alorda, S. Papanastasiou, E. Goldshtein, C. Shenderey, M. Leza, C. Pontikakos, D. Perdikis, T. Tsiligiridis, M. R. Tabilio, A. Sciarretta, C. Barceló, C. Athanassiou, M. A. Miranda, V. Alchanatis, N. Papadopoulos, and D. Nestel 2018. Electronic traps for detection and population monitoring of adult fruit flies (Diptera: Tephritidae). Journal of Applied Entomology 142: 43-51.

Smith, J. W. 1998. Boll weevil eradication: Area-wide pest management. Annals of the Entomological Society of America 91: 239-247.

Suckling, D. M., J. M. Kean, L. D. Stringer, C. Cáceres-Barrios, J. Hendrichs, J. Reyes-Flores, and B. C. Dominiak. 2016. Eradication of tephritid fruit fly pest populations: Outcomes and prospects. Pest Management Science 72: 456-465.

Southwood, T. R. E. 1978. Ecological methods: With particular reference to the study of insect populations. Chapman \& Hall. London, UK. 548 pp.

Taylor, R. A. J. 2018. Spatial distribution, sampling efficiency and Taylor's power law. Ecological Entomology 43: 215-225.

Vreysen, M. J. B. 2021. Monitoring sterile and wild insects in area-wide Integrated Pest Management programmes, pp. 485-528. In V. A. Dyck, J. Hendrichs, and A. S. Robinson (eds.), Sterile Insect Technique - Principles and practice in Area-Wide Integrated Pest Management. Second Edition. CRC Press, Boca Raton, Florida, USA.

Vreysen, M. J. B., A. S. Robinson, and J. Hendrichs (eds.). 2007. Area-wide control of pests: From research to field implementation. Springer Dordrecht, The Netherlands. 789 pp.

Zhang, J, L. Sun, Y. Liu, H. Wang, N. Sun, and P. Zhang. 2017. Mobile device-based electronic data capture system used in a clinical randomised controlled trial: Advantages and challenges. Journal of Medical Internet Research 19 (3): e66.

Zalucki, M. P., D. Adamson, and M. J. Furlong. 2009. The future of IPM: Whither or wither? Australian Journal of Entomology 48: 85-96. 